\title{
Fenomena Kondisi Sanitasi Sarana Air Bersih di Rusunawa Tanggulrejo Kecamatan Tempuran Kabupaten Magelang
}

\author{
Mahendradi $^{1}$, Ardiyansah ${ }^{2}$ \\ ${ }^{1}$ Program Studi Administrasi Publik, Universitas Tidar Magelang, Jl. Kapten Suparman \\ No.39, Tuguran, Potrobangsan, Kec. Magelang Utara, Kota Magelang, Jawa Tengah 56116 \\ 2Program Studi Manajemen, STIE Al-Khairiyah Cilegon, Jl. K.H. Ahmad Dahlan No.15, \\ Citangkil, Kec. Citangkil, Kota Cilegon, Banten 42441
}

\begin{abstract}
In 2012, Indonesia ranked the worst in the availability of clean water and suitable for Southeast Asia. There are various efforts in improving human health, one of which is by providing basic sanitation. First sanitation efforts in the community are carried out through various means, including the provision of clean water, healthy latrines, waste management, and sewerage. The conditions of households with the potential to experience a freshwater crisis include the area of flats. This study aims to provide an overview of the situation of clean water sanitation in Rusunawa Tanggulrejo, Magelang Regency. This research uses a quantitative method with a survey approach that is processed using statistics. The results found that drainage conditions, sewage disposal conditions, clean water conditions, and sanitary water flow conditions in Rusunawa Tanggulrejo are categorized as well based on the number of respondents' average responses to these conditions. Still, some things need to were made in practice, including the status of clean water sources for residents, clean water sanitation checks, and health services provided to residents of Rusunawa.
\end{abstract}

Keywords: Clean Water Sanitation Conditions, Rusunawa Tanggulrejo, and Magelang Regency

\section{Pendahuluan}

Saat ini krisis air bersih telah dialami oleh hampir seluruh negara di dunia ini. Ari bersih yang ada di dunia hanya $1 \%$ saja yang dapat dikonsumsi. $1 \%$ dari air bersih tersebut tidak semuanya dapat diakses dengan mudah oleh masyarakat. Data WHO tahun 2015 menyebutkan bahwa 663 juta penduduk masih kesulitan dalam mengkases air bersih (Rochmi, 2016). Berdasarkan hal tersebut maka diprediksikan pada tahun 2025, hampir du pertiga penduduk dunia akan bermukim di daerah-daerah yang mengalami kekurangan air (UNESCO, 2017). Di Indonesia sendiri pada tahun 2012 Lembaga Ilmu Pengetahuan Indonesia (LIPI) 
menyebutkan bahwa Indonesia menduduki peringkat terburuk dalam pelayanan ketersediaan air bersih dan layak konsumsi se-Asia Tenggara (Rochmi, 2016). Indonesia juga diprediksi akan ada 321 juta penduduk yang kesulitan mendapatkan air bersih, sebab peningkatan permintaan air bersih naik sebesar 1,33 kali, berbanding terbalik dengan jumlah penduduk yang kekurangan air (Rochmi, 2016). Untuk mengantisipasi hal tersebut dibutuhkan upaya dalam rangka meningkatkan kesehatan masyarakat.

Terdapat beberapa upaya dalam meningkatkan kesehatan manusia, salah satunya adalah dengan pemberian sanitasi dasar. Upaya sanitasi dasar pada masyarakat dilakukan melalui berbagai cara diantaranya adalah penyediaan air bersih, jamban sehat, pengelolaan sampah dan saluran pembuangan air limbah. Sanitasi memiliki berbagai manfaat bagi kesehatan terutama sanitasi di lingkungan rumah tangga. Departemen Kesehatan Republik Indonesia tahun 2004 menyebutkan bahwa sanitasi merupakan upaya kesehatan dengan cara melindungi kebersihan lingkungan dari subjeknya. Maka untuk tetap menjaga kesehatan lingkungan rumah tangga dari potensi yang merugikan kesehatan dibutuhkan sanitasi yang baik, terutama sanitasi sarana air bersih.

Rendahnya ketersediaan air bersih memberikan dampak buruk pada semua sektor, termasuk kesehatan. Disebutkan bahwa tanpa akses air minum yang higienis mengakibatkan 3.800 anak meninggal tiap hari oleh penyakit. Penyakit kolera, kurap, kudis, diare/disentri, atau thypus adalah sebagian kecil dari penyakit yang mungkin timbul jika air kotor tetap dikonsumsi (Untung, 2008). Bahkan ditemukan bahwa sanitasi dan perilaku kebersihan yang buruk serta air minum yang tidak aman berkontribusi terhadap $88 \%$ kematian anak akibat diare di seluruh dunia (Unicef Indonesia, 2012). Risiko kematian ini dapat dicegah melalui penurunan faktor lingkungan yang beresiko, yaitu dengan penyediaan air bersih, sanitasi, dan kebersihan (Chola L, Michalow J, Tugendhaft A, 2015).

Kondisi rumah tangga yang berpotensi mengalami krisis air bersih diantaranya adalah pada area rumah susun atau biasa disebut dengan rusunawa. Rusunawa atau Rumah Susun Sederhana Sewa adalah bangunan gedung bertingkat yang dibangun dalam suatu lingkungan yang terbagi dalam bagian-bagian yang distrukturkan secara fungsional dalam arah horizontal maupun vertikal dan merupakan satuansatuan yang masing-masing digunakan secara terpisah, status pengusaannya sewa serta dibangun dengan menggunakan Anggaran Pendapatan dan Belanja Negara dan atau Anggaran Pendapatan dan Belanja Daerah dengan fungsi utamanya sebagai hunian.

Pemerintah melakukan pembangunan Rusunawa dikarenakan agar masyarakat Indonesia dapat memiliki kehidupan yang layak, terjangkau dan memiliki akeses yang dekat dengan pusat kota. Namun, penyediaan sanitasi air bersih yang ada di Area Rusunawa belum sepenuhnya diterapkan oleh pengguna Rusunawa ditambah dengan masih adanya pengguna/masyarakat yang belum 
memiliki pemikiran akan pentingnya sanitasi bagi kehidupan manusia.

Berdasarkan hal tersebut penelitian ini bertujuan untuk memberikan gambaran bagaimana kondisi sanitasi air bersih yang ada di Rusunawa Tanggulrejo Kabupaten Magelang kemudian memberikan rekomendasi bagi pemerintah daerah setempat dalam menyusun kebijakan terkait pengelolaan sanitasi air bersih di lingkungan rumah susun.

\section{Metode Penelitian}

Penelitian ini menggunakan metode kuantitatif dengan pendekatan survei. Data hasil penelitian diolah menggunakan statistik dengan menggunakan pengukuran skala likert. Penelitian ini berlokasi di Rusunawa Tanggulrejo Kecamatan Tempuran Kabupaten Magelang. Sampel penelitian ini berjumlah 50 responden yang berasal dari seluruh kepala keluarga yang bertempat tinggal di Rusunawa Tanggulrejo.

\section{Hasil dan Pembahasan}

Rusunawa Tanggulrejo memiliki kapasitas 50 ruang/hunian, setelah dilakukan penelitian pada Rusunawa Tanggulrejo penghuni yang sudah menempati Rusunawa Tanggulrejo sebanyak 50 Kepala Keluarga. Sedangkan untuk jumlah penghuni Rusunawan Tanggulrejo sekitar 92 jiwa. Apabila terdapat hunian yang masih kosong akan diisi oleh penghuni yang sudah mendaftarkan sebagai calon penghuni melalui proses seleksi administrasi oleh pengelolah Rusunawa Tanggulrejo.

Berdasarkan hasil survey terdapat beberapa karakteristik responden. Penemuan lapangan menemukan sebagian besar responden berjenis kelamin laki-laki sebanyak 41 responden atau sebesar $82 \%$, hal tersebut dapat dilihat melalui tabel 1.

Tabel 1. Jumlah Responden Berdasarkan Jenis Kelamin

\begin{tabular}{|c|c|c|c|c|}
\hline \multicolumn{2}{|c|}{} & $\begin{array}{c}\text { Frequenc } \\
\mathrm{y}\end{array}$ & $\begin{array}{c}\text { Percen } \\
\mathrm{t}\end{array}$ & $\begin{array}{c}\text { Valid } \\
\text { Percen } \\
\mathrm{t}\end{array}$ \\
\hline \multirow{2}{*}{$\begin{array}{c}\text { Vali } \\
\mathrm{d}\end{array}$} & $\mathrm{L}$ & 41 & 82 & 82 \\
\cline { 2 - 5 } & $\mathrm{P}$ & 9 & 18 & 18 \\
\cline { 2 - 5 } & $\begin{array}{c}\text { Tota } \\
\text { l }\end{array}$ & 50 & 100 & 100 \\
\hline
\end{tabular}

Sumber: Data diolah, 2020

Berdasarkan tingkat pendidikan responden pengguna Rusunawa Tanggulrejo, responden paling banyak memiliki tingkat pendidikan SMA dengan jumlah 37 responden atau sekitar 74\%, secara rinci dijelaskan melalui tabel berikut.

Tabel 2. Jumlah Responden Berdasarkan Tingkat Pendidikan

\begin{tabular}{|c|c|c|c|c|}
\hline \multicolumn{2}{|c|}{} & $\begin{array}{c}\text { Frequ } \\
\text { ency }\end{array}$ & $\begin{array}{c}\text { Perc } \\
\text { ent }\end{array}$ & $\begin{array}{c}\text { Valid } \\
\text { Perc } \\
\text { ent }\end{array}$ \\
\hline \multirow{4}{*}{$\begin{array}{c}\text { Vali } \\
\text { d }\end{array}$} & SD & 1 & 2 & 2 \\
\cline { 2 - 5 } & SMP & 37 & 74 & 74 \\
\cline { 2 - 5 } & SMA & 7 & 14 & 14 \\
\cline { 2 - 5 } & $\begin{array}{c}\text { Unive } \\
\text { rsitas }\end{array}$ & 5 & 10 & 10 \\
\cline { 2 - 5 } & Total & 50 & 100 & 100 \\
\hline
\end{tabular}

Sumber: Data diolah, 2020

Setelah mengetahui karakteristik responden, kemudian berikut ini merupakan hasil penelitian tentang kondisi sanitasi air bersih yang ada di Rusunawa Tanggulrejo. Penelitian ini dilakukan untuk memberikan gambaran sanitasi sarana air bersih yang ada dilingkungan rumah tangga khususnya lingkungan Rusunawa, 
setelah itu kriteria perhutungan kondisi sanitasi di lingkungan Rusunawa dapat diketahui melalui pengukuran nilai rata-rata pada setiap jawaban responden yang kemudian di kriterianya ditentukan oleh tabel yang telah ditentukan.

Tabel 3. Kondisi Drainase

\begin{tabular}{|c|c|c|c|c|}
\hline \multicolumn{2}{|c|}{} & $\begin{array}{c}\text { Frequenc } \\
\mathrm{y}\end{array}$ & $\begin{array}{c}\text { Percen } \\
\mathrm{t}\end{array}$ & $\begin{array}{c}\text { Valid } \\
\text { Percen } \\
\mathrm{t}\end{array}$ \\
\hline \multirow{4}{*}{$\begin{array}{c}\text { Vali } \\
\mathrm{d}\end{array}$} & 1 & 0 & 0 & 0 \\
\cline { 2 - 5 } & 2 & 6 & 12 & 6 \\
\cline { 2 - 5 } & 3 & 15 & 30 & 10 \\
\cline { 2 - 5 } & 4 & 29 & 58 & 84 \\
\cline { 2 - 5 } & $\begin{array}{c}\text { Tota } \\
\text { l }\end{array}$ & 50 & 100 & 100 \\
\hline
\end{tabular}

Sumber: Data diolah, 2020

Berdasarkan tabel 3 diketahui bahwa sebagian besar responden menjawab kondisi drainase di Rusunawa Tanggulrejo dalam kategori baik, hal ini ditunjukan dengan 29 responden atau sekitar $58 \%$ menjawab hal tersebut.

Tabel 4. Kondisi Pembuangan Limbah

\begin{tabular}{|c|c|c|c|c|}
\hline \multicolumn{2}{|c|}{} & $\begin{array}{c}\text { Frequenc } \\
\mathrm{y}\end{array}$ & $\begin{array}{c}\text { Percen } \\
\mathrm{t}\end{array}$ & $\begin{array}{c}\text { Valid } \\
\text { Percen } \\
\mathrm{t}\end{array}$ \\
\hline \multirow{4}{*}{$\begin{array}{c}\text { Vali } \\
\mathrm{d}\end{array}$} & 1 & 0 & 0 & 0 \\
\cline { 2 - 5 } & 2 & 7 & 14 & 6 \\
\cline { 2 - 5 } & 4 & 10 & 20 & 10 \\
\cline { 2 - 5 } & $\begin{array}{c}\text { Tota } \\
\text { l }\end{array}$ & 50 & 100 & 100 \\
\hline
\end{tabular}

Sumber: Data diolah, 2020

Berdasarkan tabel 4 diketahui bahwa sebanyak 33 responden atau sekitar 66\% responden menjawab kondisi pembuangan limbah dalam kategori baik, sedangkan sisanya 10 responden atau $20 \%$ responden menjawab cukup baik, dan sisanya 7 responden atau $14 \%$ responden menjawab kurang baik.

Tabel 5. Pengecekan Sanitasi

\begin{tabular}{|c|c|c|c|c|}
\hline \multicolumn{2}{|c|}{} & $\begin{array}{c}\text { Frequenc } \\
\mathrm{y}\end{array}$ & $\begin{array}{c}\text { Percen } \\
\mathrm{t}\end{array}$ & $\begin{array}{c}\text { Valid } \\
\text { Percen } \\
\mathrm{t}\end{array}$ \\
\hline \multirow{4}{*}{$\begin{array}{c}\text { Vali } \\
\text { d }\end{array}$} & 1 & 6 & 12 & 12 \\
\cline { 2 - 5 } & 2 & 2 & 4 & 4 \\
\cline { 2 - 5 } & 4 & 7 & 14 & 14 \\
\cline { 2 - 5 } & $\begin{array}{c}\text { Tota } \\
\text { l }\end{array}$ & 55 & 70 & 70 \\
\hline
\end{tabular}

Sumber: Data diolah, 2020

Berdasarkan tabel 5 diketahui terdapat 35 responden yang menjawab pengecekan sanitasi yang dilakukan apabila dibutuhkan saja, sedangkan 7 responden menjawab pengecekan sanitasi dilakukan selama 6 bulan sekali, 2 responden menjawab pengecekan dilakukan setiap 3 bulan, dan 6 responden menjawab pengecekan sanitasi dilakukan setiap bulan.

Tabel 6. Sumber Air Bersih

\begin{tabular}{|c|c|c|c|c|}
\hline \multicolumn{2}{|c|}{} & $\begin{array}{c}\text { Frequenc } \\
\mathrm{y}\end{array}$ & $\begin{array}{c}\text { Percen } \\
\mathrm{t}\end{array}$ & $\begin{array}{c}\text { Valid } \\
\text { Percen } \\
\mathrm{t}\end{array}$ \\
\hline \multirow{4}{*}{$\begin{array}{c}\text { Vali } \\
\mathrm{d}\end{array}$} & 1 & 1 & 2 & 2 \\
\cline { 2 - 5 } & 2 & 37 & 74 & 74 \\
\cline { 2 - 5 } & 4 & 6 & 12 & 12 \\
\cline { 2 - 5 } & $\begin{array}{c}\text { Tota } \\
\mathrm{l}\end{array}$ & 50 & 12 & 12 \\
\hline
\end{tabular}

Sumber: Data diolah, 2020

Berdasarkan tabel 6 diketahui bahwa sebanyak 37 responden atau sekitar $74 \%$ responden menyatakan sumber air di Rusunawa Tanggulrejo dalam keadaan kurang baik, sedangkan sisanya masing-masing 6 responden atau $12 \%$ responden menjawab baik dan cukup baik. 
Tabel 7. Kondisi Air

\begin{tabular}{|c|c|c|c|c|}
\hline \multicolumn{2}{|c|}{} & $\begin{array}{c}\text { Frequenc } \\
\mathrm{y}\end{array}$ & $\begin{array}{c}\text { Percen } \\
\mathrm{t}\end{array}$ & $\begin{array}{c}\text { Valid } \\
\text { Percen } \\
\mathrm{t}\end{array}$ \\
\hline \multirow{4}{*}{ Valid } & 1 & 0 & 0 & 0 \\
\cline { 2 - 5 } & 2 & 3 & 6 & 6 \\
\cline { 2 - 5 } & 3 & 5 & 10 & 10 \\
\cline { 2 - 5 } & 4 & 42 & 84 & 84 \\
\cline { 2 - 5 } & Total & 50 & 100 & 100 \\
\hline
\end{tabular}

Sumber: Data diolah, 2020

Berdasarkan tabel 7 diketahui bahwa sebanyak 42 responden atau sekitar 84\% responden menyatakan kondisi air di Rusunawa Tanggulrejo sudah baik, sedangkan sisanya 5 responden atau sekitar $10 \%$ responden menyatakan cukup baik dan sisanya 3 responden atau sekitar $6 \%$ menyatakan kurang baik.

Tabel 8. Kondisi Aliran Air

\begin{tabular}{|c|c|c|c|c|}
\hline \multicolumn{2}{|c|}{} & $\begin{array}{c}\text { Frequenc } \\
\mathrm{y}\end{array}$ & $\begin{array}{c}\text { Percen } \\
\mathrm{t}\end{array}$ & $\begin{array}{c}\text { Valid } \\
\text { Percen } \\
\mathrm{t}\end{array}$ \\
\hline \multirow{7}{*}{ Valid } & 1 & 1 & 2 & 2 \\
\cline { 2 - 5 } & 2 & 0 & 0 & 0 \\
\cline { 2 - 5 } & 3 & 11 & 22 & 22 \\
\cline { 2 - 5 } & 4 & 38 & 76 & 76 \\
\cline { 2 - 5 } & $\begin{array}{c}\text { Tota } \\
1\end{array}$ & 50 & 100 & 100 \\
\hline
\end{tabular}

Sumber: Data diolah, 2020

Berdasarkan tabel 8 diketahui bahwa sebanyak 38 responden atau sekitar $76 \%$ responden menjawab kondisi aliran air dalam kategori baik, sedangkan sisanya 11 responden atau sekitar $22 \%$ responden manyatakan kondisi aliran air di cukup baik.

Tabel 9. Pelayanan Kesehatan yang diberikan Pemerintah

\begin{tabular}{|c|c|c|c|c|}
\hline \multicolumn{2}{|c|}{} & $\begin{array}{c}\text { Frequenc } \\
\mathrm{y}\end{array}$ & $\begin{array}{c}\text { Percen } \\
\mathrm{t}\end{array}$ & $\begin{array}{c}\text { Valid } \\
\text { Percen } \\
\mathrm{t}\end{array}$ \\
\hline \multirow{4}{*}{$\begin{array}{c}\text { Vali } \\
\mathrm{d}\end{array}$} & 1 & 46 & 92 & 92 \\
\cline { 2 - 5 } & 2 & 4 & 8 & 8 \\
\cline { 2 - 5 } & 4 & 0 & 0 & 0 \\
\cline { 2 - 5 } & $\begin{array}{c}\text { Tota } \\
1\end{array}$ & 50 & 100 & 100 \\
\hline
\end{tabular}

Berdasarkan tabel 9 diketahui bahwa sebanyak 46 responden atau sekitar 92 responden menyatakan pelayanan kesehatan yang diberikan kepada masyarakat Rusunawa berada pada kategori tidak baik, sedangkan sisanya sebanyak 4 responden atau sekitar 8\% responden menyatakan kurang baik. 
Tabel 10. Rekapitulasi Hasil Perhitungan

\begin{tabular}{|c|c|c|c|c|c|c|c|}
\hline \multirow{2}{*}{ Indikator } & \multicolumn{4}{|c|}{ Jumlah } & \multirow{2}{*}{ Sampel } & \multirow{2}{*}{ Jumlah Nilai } & \multirow{2}{*}{$\begin{array}{c}\text { Rata-rata } \\
\text { Nilai }\end{array}$} \\
\hline & 4 & 3 & 2 & 1 & & & \\
\hline Kondisi drainase & 29 & 15 & 6 & - & 50 & 173 & 3.46 \\
\hline $\begin{array}{l}\text { Kondisi } \\
\text { pembuangan } \\
\text { limbah }\end{array}$ & 33 & 10 & 7 & - & 50 & 176 & 3.52 \\
\hline $\begin{array}{l}\text { Pengecekan } \\
\text { Sanitasi }\end{array}$ & 35 & 7 & 2 & 6 & 50 & 171 & 3.42 \\
\hline $\begin{array}{l}\text { Sumber air } \\
\text { bersih }\end{array}$ & 6 & 6 & 37 & 1 & 50 & 117 & 2.34 \\
\hline $\begin{array}{l}\text { Kondisi air } \\
\text { bersih }\end{array}$ & 42 & 5 & 3 & - & 50 & 189 & 3.78 \\
\hline $\begin{array}{l}\text { Kondisi aliran air } \\
\text { bersih }\end{array}$ & 38 & 11 & - & 1 & 50 & 186 & 3.72 \\
\hline $\begin{array}{l}\text { Pelayanan } \\
\text { kesehatan }\end{array}$ & - & - & 4 & 46 & 50 & 54 & 1.08 \\
\hline \multicolumn{6}{|c|}{ Jumlah } & 1066 & 3.05 \\
\hline
\end{tabular}

Sumber: Data diolah, 2020

Berdasarkan rekapitulasi perhitungan jumlah rata-rata skor setiap indikator, maka diketahui bahwa nilai rata-rata responden adalah sebesar 3,05. apabila diukur berdasarkan kategorisasi ukuran nilai maka nilai tersebut berada pada interval 2,25-3,25 atau berada pada kategori cukup baik. Secara lengkap dijelaskan dalam tabel 11.

Tabel 11. Kategorisasi Ukuran Nilai

\begin{tabular}{|c|c|}
\hline Kriteria & $\begin{array}{c}\text { Nilai } \\
\text { Interval }\end{array}$ \\
\hline Tidak Baik & $1,00-1,75$ \\
\hline Kurang Baik & $1,75-2,25$ \\
\hline Cukup Baik & $2,25-3,25$ \\
\hline Sangat Baik & $3,25-4,00$ \\
\hline
\end{tabular}

Secara keseluruhan kondisi sanitasi sarana air bersih di lingkungan Rusunawa sudah cukup baik, namun ada beberapa indikator yang dirasa masih kurang baik. Adapun indikator tersebut adalah sumber air bersih, pengecekan sanitasi dan pelayanan kesehatan yang diberikan kepada warga Rusunawa.

berdasarkan hasil wawancara
sebagian besar warga rusunawa menyatakan sumber air bersih didapatkan dari sumur bor yang kemudian ditampung kedalam penampungan air. Namun kondisinya dirasa kurang baik, untuk itu kiranya pemerintah daerah perlu membuat kebijakan dalam rangka membuat saluran pipa air dari PDAM agar sumber air di lingkungan Rusunawas lebih baik. Kemudian hal lain yang perlu menjadi perhatian pada sanitasi air bersih di Rusunawa Tanggulrejo adalah pengecekan sanitasi yang seharusnya dilakukan secara rutin, ini perlu mendapat dukungan dari seluruh masyarakat penghuni Rusunawa melalui upaya partisipasi. Partisipasi warga semakin dipandang sebagai alat untuk mencapai beberapa tujuan yang potensial. Misalnya, partisipasi warga dapat digunakan untuk memberi informasi kepada publik, mengeksplorasi masalah, mendapatkan umpan balik, menghasilkan ide, mengumpulkan data, dan atau mengembangkan kapasitas atau tindakan kolaboratif (Nabatchi, 2012). 
Kemudian hal lain yang perlu mendapat perhatian pemerintah daerah adalah pemberian layanan kesehatan pada warga Rusunawa. Kualitas sanitasi yang buruk akan berdampak langsung pada kondisi kesehatan warga Rusunawa, maka untuk itu Pemerintah Daerah harus sesering mungkin melakukan pengecekan kesehatan terhadap warga Rusunawa, agar warga yang sakit karena kondisi sanitasi yang kurang baik bisa cepat diatasi oleh petugas kesehatan.

\section{Kesimpulan}

Air merupakan salah satu kebutuhan pokok yang pasti dibutuhkan oleh manusia. Air yang dipakai setiap harinya oleh manusia berhubungan erat dengan kesehatan. Apabila tidak diperhatikan sumber dan standar kesehatannya, maka air dapat menjadi media dalam penyebaran penyakit. Untuk itu sanitasi sarana air bersih dibutuhkan di seluruh lingkungan tempat tinggal rumah tangga. Berdasarkan hasil penelitian diketahui bahwa kondisi sanitasi air bersih di Rusunawa Tanggulrejo sudah cukup baik, namun ada beberapa yang perlu dilakukan perbaikan diantaranya, penggunaan sumber air bersih, pengecekan sanitasi air bersih dan pelayanan kesehatan yang diberikan kepada warga Rusunawa.

\section{Referensi}

Chola L, Michalow J, Tugendhaft A, and H. K. (2015). Reducing diarrhoea deaths in South Africa: costs and effects of scaling up essential interventions to prevent and treat diarrhoea in under five children. BMC Public
Health, 15(394), 1-10.

Nabatchi, T. (2012). A manager's guide to evaluating citizen participation. IBM Center for the Business of Government.

Putri Yundari IGA. (2012). Hubungan antara Faktor Sanitasi Lingkungan dengan Kejadian Diare Pada Balita di Desa Kukuh Kabupaetn Tabanan 2012. Poltekkes Denpasar.

Rochmi, M. (2016). Akses air bersih masih jauh dari target. https://beritagar.id/artikel/edit orial/hapuskan -perdapenyebabekonomi-biaya-tinggi

Undang-undang Nomor 20 Tahun 2011. (2011). 66, ננ וטע על ון, 37-39.

UNESCO. (2017). Global Climate Change. www.unesco.org.

Unicef Indonesia. (2012). Ringkasan Kajian: Air Bersih, Sanitasi, \& Kebersihan.

https://www.unicef.org/indones ia/id/A8__B_Ringkasan_Kajian_Air_Bersih. pdf.

Untung, O. (2008). Menjernihkan air kotor. Pustaka Pembangunan Swadaya Nusantara. 